\title{
Performance Evaluation of Waterflood Reservoirs in High Water Cut Period Based on New Relative Permeability Model
}

\author{
Haijun Fan \\ School of Petroleum Engineering, China University of Petroleum, Qingdao, China
}

\section{Email address:}

petroengineer@126.com

\section{To cite this article:}

Haijun Fan. Performance Evaluation of Waterflood Reservoirs in High Water Cut Period Based on New Relative Permeability Model. Petroleum Science and Engineering. Vol. 4, No. 2, 2020, pp. 64-69. doi: 10.11648/j.pse.20200402.13

Received: September 18, 2020; Accepted: October 5, 2020; Published: October 13, 2020

\begin{abstract}
Water flooding performance evaluation and recovery prediction with relatively easy tools has always been among the top aims of reservoir engineering studies, especially for mature reservoirs in high water-cut period. Relative permeability curves are basic required properties reflecting multi-phase flow characteristic and used together with production history to evaluate reservoir performance. In high water-cut period the relative permeability ratio deviate from the empirical straight-line form, which makes traditional models less effective or erroneous in performance prediction. This paper presents a new relative permeability ratio model which can convert the non-linear characteristic of this problem into linear expression. And a new simple water flooding performance analysis technique is developed based on the new model, which can be used to forecast ultimate recovery factor and the corresponding sweep efficiency. The main advantage of this work is taking into account of high water-cut characteristic with less model parameters compared with other improved models. Synthetic case and field examples demonstrated the advantages of this method in parameter solving and consistency in history matching. The proposed technique in this work can be used as predictive analysis tool in forecasting ultimate recovery and performance evaluation for mature water flooding reservoirs.
\end{abstract}

Keywords: Water Flooding Performance, Relative Permeability, Recovery Factor, High Water-cut

\section{Introduction}

Many sophisticated simulation software are available in water flooding performance evaluation and recovery prediction, nevertheless petroleum engineers are still in need of simple tools or correlations for dynamic analysis due to time-consuming or data shortage. Pure "data-driven" analysis of reservoir performance cannot reasonably interpret the nature of multi-phase flow in reservoirs and may bring wrong predictions even under a good history match study. So the use of relative permeability together with production history provides an effective way in reservoir performance evaluation, combining flow mechanism and production practice.

Over the past decades of years water-oil ratio (WOR) analysis has been widely used for performance evaluation and production forecasting for water flooding reservoirs. Some empirical relations have been presented and accepted in oil field practice.

Ershagi and Omoregie [1] presented a recovery ratio and water-cut relation called "X-plot", as shown in equation (1), based on the concepts of fractional flow and the frontal advance theory (Buckley and Leverett), which can predict recoverable oil volume by extrapolating the curve to arbitrary value of water-cut $\left(f_{\mathrm{w}}\right)$.

$$
E_{r}=a_{e r}+b_{e r} X
$$

In equation (1) $E_{\mathrm{r}}$ is the recovery ratio, which can be calculated by cumulative oil production divided by oil in place $\left(N_{\mathrm{p}} / N\right), X$ is a function of water-cut $\left(f_{\mathrm{w}}\right)$, and the constants $a_{\text {er }}$ and $b_{\mathrm{er}}$ have dependency on a linear relative permeability ratio relation as described in Appendix 1.

Lo [2] suggested using a logarithm relationship of WOR and $N_{\mathrm{p}}$, in which the coefficient constants can be determined by the straight-line relationship of relative permeability ratio and water saturation either, as described in Appendix 2. 
Over the past decade some researchers began to realize that the straight-line relationship would not exist when water saturation is close to large value in late production stage of oilfield as shown in Figure 1. In high water-cut period the relative permeability ratio deviate from the empirical straight-line form, which makes traditional models less effective or erroneous in performance prediction, leading to an over-estimation of recoverable oil.

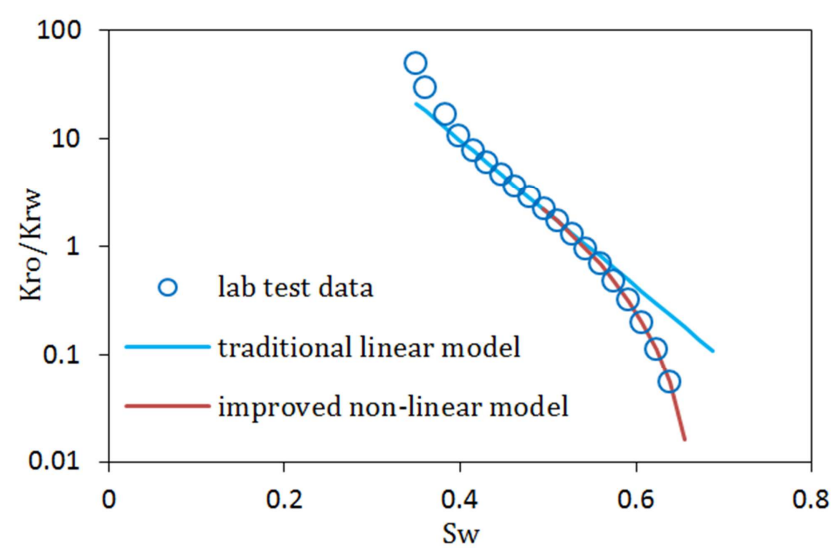

Figure 1. Non-linear match of relative permeability ratio.

Yortos, et al. [3] divided the relative permeability curve into two separate regions, as "exponential" and "power-low" region. B. Can [4] proposed a nonlinear relative permeability ratio relation and presented a modified Y-Function model to evaluate performance of water following. Nevertheless, the application comparison of the modified Y-function model with other five commonly used models did not show any advantage over Arp's decline model. Other researchers [5-7] provided different models for the relative permeability ratio and developed different performance prediction models, shown in Table 1. These improved models have not obtained wide application because of tedious unknown-parameter matching and solving problems or generating inconsistency with real reservoir performance.

Table 1. List of the non-linear relative permeability ratio models.

\begin{tabular}{lll}
\hline Year & Author & Relative Permeability Ratio Model \\
\hline 2011 & LIU S. & $k_{r o} / k_{r w}=a e^{-b \cdot c^{S_{w}}}$ \\
2013 & Song Z. & $k_{r o} / k_{r w}=d e^{-\left(a S_{w}^{2}+b S_{w}\right)}$ \\
2013 & HOU J. & $\ln \left(k_{r o} / k_{r w}\right)=m+n S_{w}+p e^{S_{w}}$ \\
2014 & B. Can & $k_{r o} / k_{r w}=A e^{-B S_{w}^{C}}$ \\
\hline
\end{tabular}

\section{New Model Development}

\subsection{Derivation of New Performance Evaluation Model}

For oil/water relative permeability curve, a normalized water saturation can be defined according to the following equation, equivalent to a theoretical recovery ratio.

$$
S_{w d}=\left(S_{w}-S_{w i}\right) /\left(1-S_{w i}\right)
$$

After analyzing of a large quantity of reservoir relative permeability curves, we found that relative permeability ratio $k_{\mathrm{rw}} / k_{\mathrm{ro}}$ and normalized water saturation $S_{\mathrm{wd}}$ shows a mathematical relation which can be described by equation (3). Figure 2 shows some of the new plots based on examples from real reservoirs.

$$
\frac{k_{r w}}{k_{r o}}=\frac{b S_{w d}}{\left(1-S_{w d}\right)^{n}}
$$

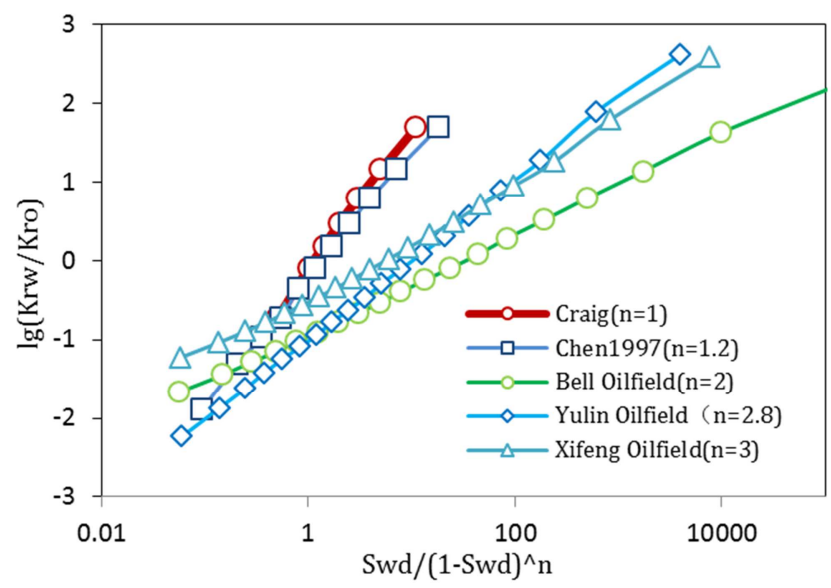

Figure 2. New relative permeability ratio model for different oilfields.

The advantage of this new relative permeability model is that it convert the non-linear characteristic into a new straight line form with two parameters and is capable of depicting the whole life time of the reservoir, no need to distinguish high water-cut period. Based on equation (3) a new water flooding performance model has been developed (as in Appendix 3).

$$
\lg (W O R / R)=m-n \lg \left(E_{d}-R\right)
$$

In which $m$ and $n$ are constants and $n$ is the same as in the relative permeability ratio, $R$ is recovery ratio, $E_{\mathrm{d}}$ is the waterflood displacing efficiency.

The model in equation (4) can be applied by production history matching based on oil and water production data. A final straight-line can be found by assuming an appropriate displacing efficiency $E_{\mathrm{d}}$ according to representative relative permeability curve or rock core lab test. The ultimate recovery factor $E_{\mathrm{R}}$ can be derived by solving $R$ value in equation (4) when $W O R$ reaches a limit value, such as $W O R=49$. Another application of the new model is to estimate reservoir conformance, or sweep efficiency, according to the definition of recovery factor.

$$
E_{V}=E_{R} / E_{d}
$$

The steps of using this model are described by following in section 2.2 and Figure 3.

\subsection{Steps for Recovery Prediction Based on New Model}

(1) Read relative permeability curve data and reservoir production history; 
(2) Normalize $k_{\mathrm{rw}} / k_{\mathrm{ro}}$ vs. $S_{\mathrm{wd}}$, determine index value of $n$ and displacing efficiency $E_{\mathrm{d}}$;

(3) Do linear regression of $W O R / R$ with $\left(E_{\mathrm{d}}-R\right)$, determine the slope $n$;

(4) Check the two values of $n$ from these two methods, if consistent with each other then go to next step, otherwise adjust or input new relative permeability and assume new $E_{\mathrm{d}}$ value;

(5) After $W O R / R$ model determined, input the limit value of $W O R$, solve the $R$ value as ultimate recovery $E_{\mathrm{R}}$ by the $W O R / R$ model, then estimate sweep efficiency by $E_{\mathrm{v}}=E_{\mathrm{R}} / E_{\mathrm{d}}$

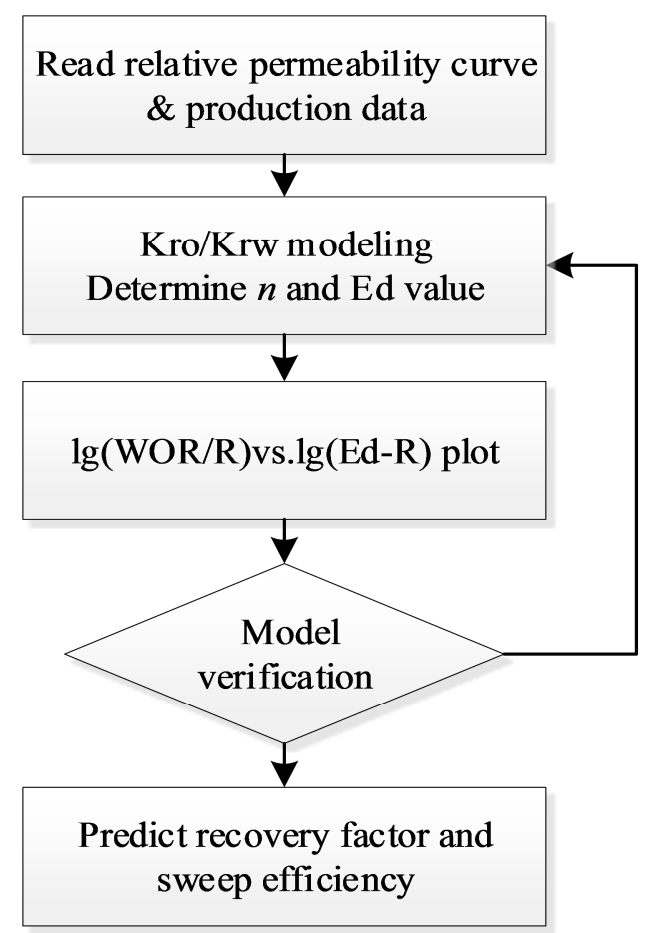

Figure 3. Reservoir performance prediction process with new models.

\section{Case Study}

\subsection{Case Analysis 1: Synthetic Case-Linear Water Drive}

A synthetic line-water-drive reservoir is designed with an OOIP of $26.4 \times 10^{4}$ ton. The reservoir permeability is $280 \mathrm{mD}$ and oil viscosity is $20 \mathrm{mPa} \cdot \mathrm{s}$. The reservoir produce under a line water drive with pressure difference of $2 \mathrm{MPa}$ and injection-production distance is $500 \mathrm{~m}$. The relative permeability and the production performance calculated based on 1D Buckley-Leverett theory are list in Table 2.

Table 2. Relative permeability and production performance in case 1.

\begin{tabular}{llllll}
\hline $\mathbf{S}_{\mathbf{w}} / \mathbf{f}$ & $\mathbf{k}_{\mathbf{r o}} / \mathbf{f}$ & $\mathbf{k}_{\mathbf{r w}} / \mathbf{f}$ & $\mathbf{f}_{\mathbf{w}} / \mathbf{f}$ & $\mathbf{N}_{\mathbf{p}} / \mathbf{1 0} \mathbf{4}_{\mathbf{t}}$ & $\mathbf{R} / \mathbf{f}$ \\
\hline 0.5653 & 0.2399 & 0.0544 & 0.6940 & 13.2231 & 0.5009 \\
0.5865 & 0.2016 & 0.0686 & 0.7729 & 13.7512 & 0.5209 \\
0.6078 & 0.1666 & 0.0850 & 0.8361 & 14.3533 & 0.5437 \\
0.6290 & 0.1349 & 0.1038 & 0.8850 & 14.9807 & 0.5675 \\
0.6502 & 0.1066 & 0.1252 & 0.9215 & 15.7830 & 0.5978 \\
0.6820 & 0.0704 & 0.1626 & 0.9585 & 16.7038 & 0.6327 \\
0.7245 & 0.0337 & 0.2230 & 0.9851 & 17.6594 & 0.6689 \\
0.7563 & 0.0150 & 0.2770 & 0.9946 & 18.6697 & 0.7072 \\
\hline
\end{tabular}

Figure 4 shows the relative permeability curve and $\mathrm{k}_{\mathrm{ro}} / \mathrm{k}_{\mathrm{rw}}$ ratio match. It is clear that the mid-term straight-line trend does not exist in the later region of water saturation, indicating two-phase flow nature of high water cut period. The new relative permeability ratio model in this paper provides a good match. Figure 5 shows the match of $W O R / R$ relation and the predicted recovery factor is $70.6 \%$ under a limit water-cut value of $99 \%$, which is in high consistency with the theoretical calculation in Table 1.

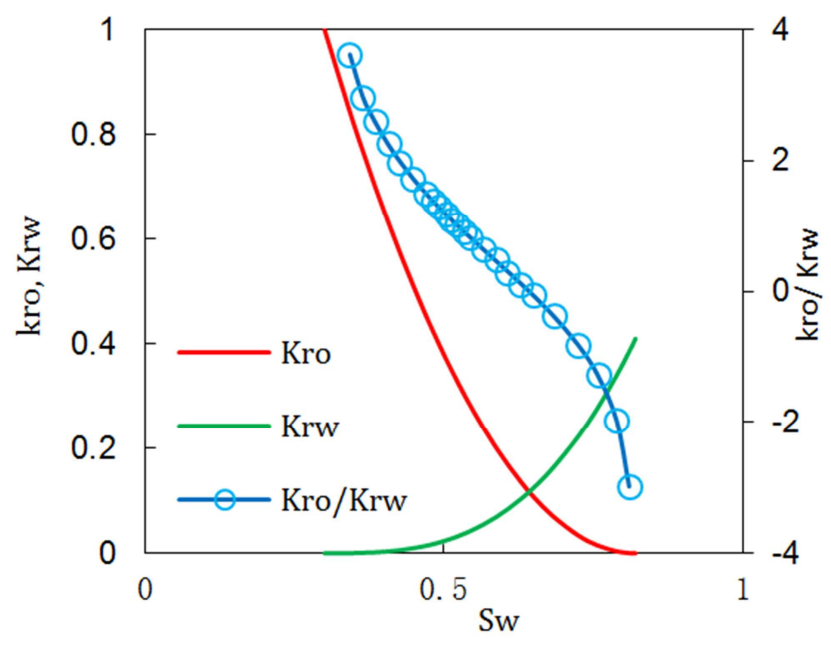

Figure 4. Relative permeability ratio in case 1.

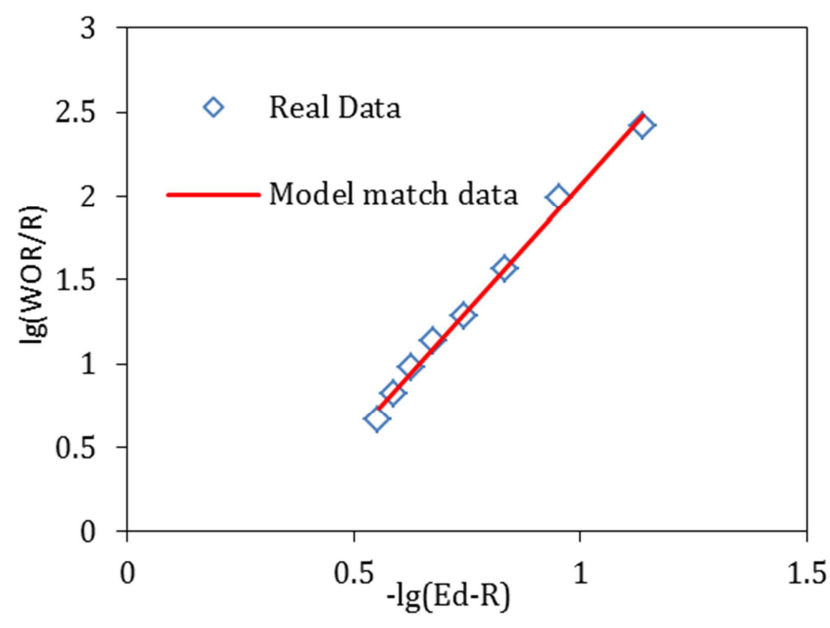

Figure 5. Match of WOR/R model in case 1 .

\subsection{Case Analysis 2: Gudong Oilfield Performance Analysis}

This reservoir is from Gudong Oilfield No7 block which is undergoing a quick water-cut rising after the adjustment in 2003. The water cut is above $95 \%$. By assuming $E_{\mathrm{d}}=0.7$, the $W O R / R$ straight-line relation is derived after history match and the $n$ value is 5.7167, which is consistent with the index value in relative permeability ratio.

$$
\lg (W O R / R)=-0.776-5.7167 \lg \left(E_{d}-R\right)
$$

A recovery factor of $38.6 \%$ is obtained by solving $R$ in the 
above equation based on a limit value of WOR as 49. This value is close to the recovery factor of $39 \%$ derived by Wang [8]. And the sweep efficiency $E_{\mathrm{v}}$ is equal to $0.386 / 0.7=0.55$, which is very low considering the long water injection history, indicating a high heterogeneity of this reservoir.

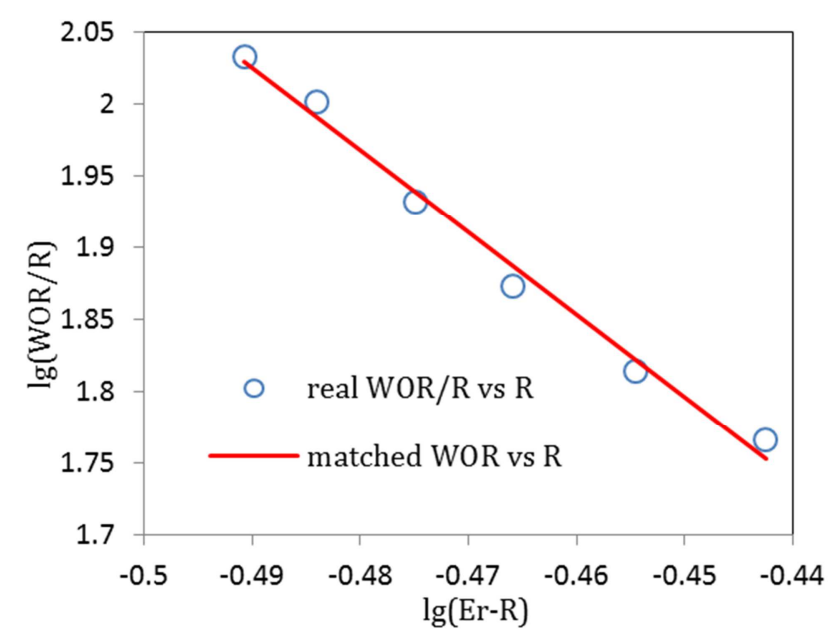

Figure 6. WOR/R relation match of Gudong 7 Block.

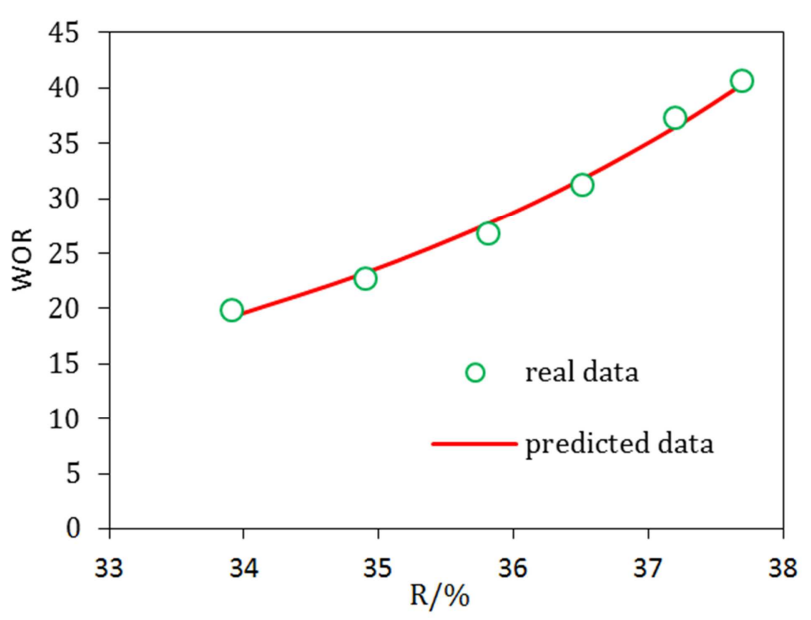

Figure 7. WOR vs R match of Gudong 7 Block.

\subsection{Case Analysis 3: Sabei Transition Block}

The Sabei transition block is from Daqing oilfield which was analyzed by Chen [9] based on production history. The $W O R / R$ relation is derived according to the new model in this work:

$$
\lg (W O R / R)=-0.0149-4.4977 \lg \left(E_{d}-R\right)
$$

The displacing efficiency $E_{\mathrm{d}}$ is 0.75 from relative permeability curve and the recovery factor from the new model is $40.8 \%$, which is almost close to the result $39.6 \%$ given by previous study [9]. The calculated sweep efficiency is 0.544 , so effective measures should be considered to improve the water flooding effects in this transition zone. Figure 8 shows the match of $W O R / R$ vs $\left(E_{\mathrm{d}}-R\right)$ in equation (7). It is evident that the linear approximation is valid at high water/oil ratio. After convert the $W O R$ to $f_{\mathrm{w}}$, a good match of water-cut is shown as in Figure 9.

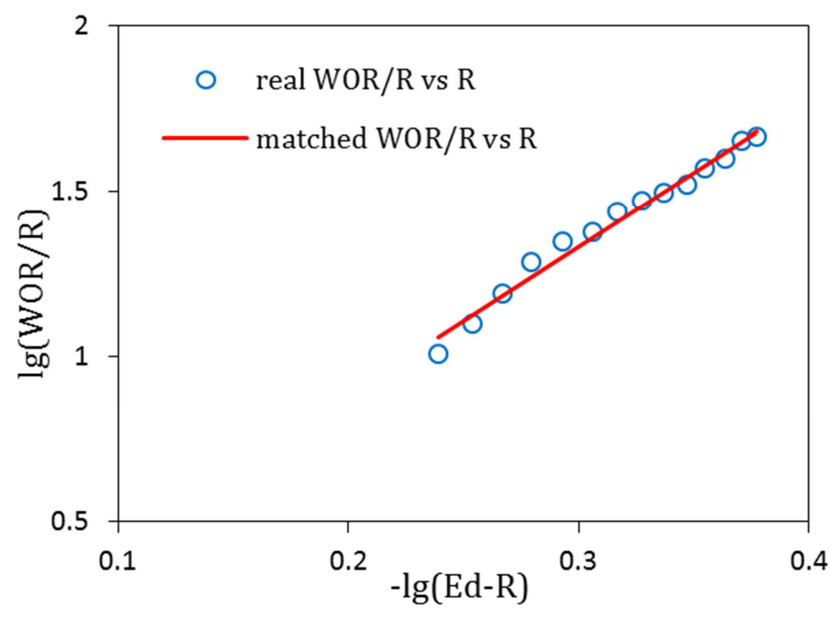

Figure 8. WOR/R relation match of Sabei Block.

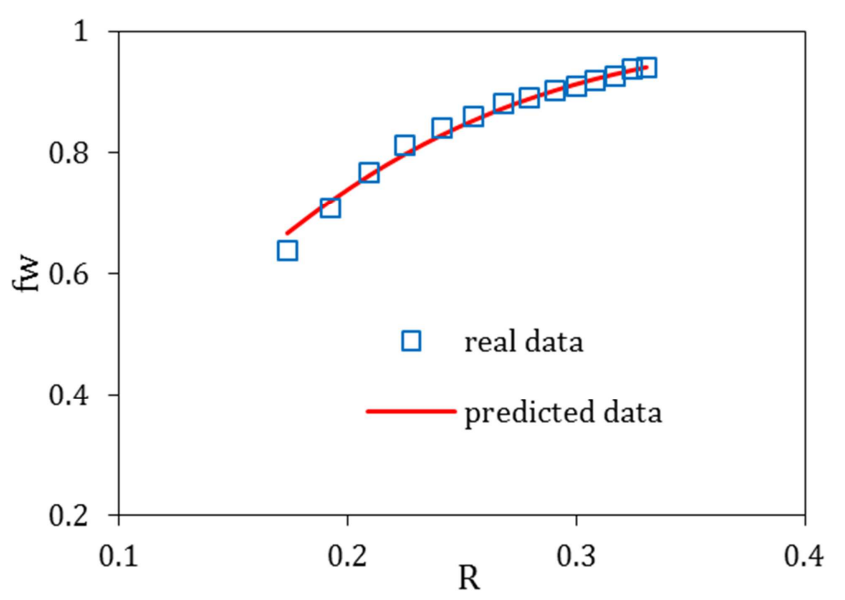

Figure 9. $f_{w}$ vs $R$ match of Sabei Block.

\section{Conclusion}

A simple $W O R / R$ water flooding performance analysis technique is developed based on new oil/water relative permeability ratio model which converts the non-linear $k_{\mathrm{ro}} / k_{\mathrm{rw}}$ relation into a linear expression with limited parameters. The proposed technique in this work provides an effective and useful predictive analysis tool in forecasting ultimate recovery and performance evaluation for mature water flooding reservoirs. The three key indexes for reservoir waterflood performance evaluation, displacing efficiency, recovery factor and sweep efficiency can be estimated simultaneously. Model analysis and field case studies show the benefits of this method in parameter solving and consistency in history matching. The new method has both accuracy and simplicity for performance evaluation of mature oil field in high water-cut period.

\section{Appendix}

1. Ershagi and Omoregie "X-plot" model

Ershagi and Omoregie (1978) presentd recovery ration and 
water cut relation called "X-plot" based on the concepts of fractional flow and the frontal advance theory (Buckley and Leverett).

$$
E_{r}=a_{e r}+b_{e r} X
$$

In which,

$$
\begin{gathered}
X=\ln \left(\frac{1}{f_{w}}-1\right)-\frac{1}{f_{w}}, b_{e r}=\frac{1}{b\left(1-S_{w i}\right)} \\
a_{e r}=-\frac{1}{1-S_{w i}}\left(S_{w i}+\frac{1}{b} \ln C\right), C=a\left(\frac{\mu_{w}}{\mu_{o}}\right)
\end{gathered}
$$

The coefficients $a$ and $b$ are obtained from the following empirical relative permeability ratio straight-line relationship.

$$
\log \left(k_{r o} / k_{r w}\right)=\log (a)+b S_{w}
$$

2. Lo K. WOR vs. $\mathrm{N}_{\mathrm{p}}$ relation

Lo (1990) suggested using a logarithm relationship of WOR and $N_{\mathrm{p}}$

$$
\log (W O R)=\frac{b\left(1-S_{w c}\right)}{O O I P} N_{p}+\log \left(\frac{a \mu_{o}}{\mu_{w}}\right)+b S_{w c}-\frac{1}{\ln 10}
$$

In which the constants $a$ and $b$ are determined by the relationship of relative permeability ratio and water saturation, as described by (9).

3 . New relative permeability ratio and performance model

Define normalized water saturation $S_{\mathrm{wd}}$,

$$
S_{w d}=\frac{S_{w}-S_{w i}}{1-S_{o r}-S_{w i}}
$$

In which, $S_{\mathrm{wi}}$ is the connate water saturation, $S_{\mathrm{or}}$ is the residual oil saturation.

A relation of relative permeability ratio and $S_{\mathrm{wd}}$ is found by analyzing a large quantity of field examples.

$$
\frac{k_{r w}}{k_{r o}}=\frac{b S_{w d}}{\left(1-S_{w d}\right)^{n}}
$$

In which $b$ and $n$ are two constants which can be determined by data matching.

For water flooding reservoir, the recovery ratio can be defined by:

$$
R=\frac{N_{p}}{N}=\frac{S_{w}-S_{w i}}{1-S_{w i}}
$$

In which $N_{\mathrm{p}}$ is cumulative oil production, $N$ is the oil in place.

Combining (11) and (13), it gives,

$$
R=\frac{1-S_{o r}-S_{w i}}{1-S_{w i}} S_{w d}
$$

In which $\left(1-S_{o r}-S_{w i}\right) /\left(1-S_{w i}\right)$ is the waterflood displacing efficiency which can be expressed as $E_{\mathrm{d}}$, so we have

$$
S_{w d}=\frac{R}{E_{d}}
$$

Under steady state flow, the water-oil ratio is defined as:

$$
W O R=\frac{Q_{w}}{Q_{o}}=\frac{\mu_{o} B_{o} \gamma_{w}}{\mu_{w} B_{w} \gamma_{o}} \frac{k_{r w}}{k_{r o}}
$$

Substitute (12) and (15) into (16), it gives:

$$
\frac{W O R}{R}=\frac{b \mu_{o} B_{o} \gamma_{w}}{\mu_{w} B_{w} \gamma_{o}} \frac{E_{d}^{n-1}}{\left(E_{d}-R\right)^{n}}
$$

Take logarithm of (17) on both sides, the final form of the new model is:

$$
\lg \frac{W O R}{R}=m-n \lg \left(E_{d}-R\right)
$$

In which, $m=\lg \frac{b \mu_{o} B_{o} \gamma_{w} E_{d}^{n-1}}{\mu_{w} B_{w} \gamma_{o}}$

Where $\mu_{o}$ is oil viscosity, $\mathrm{mPa} \cdot \mathrm{s}, \mu_{w}$ is water viscosity, $\mathrm{mPa} \cdot \mathrm{s} ; B_{o}$ is oil formation volume factor, $B_{w}$ is water formation volume factor; $\gamma_{o}$ is surface oil density, $\mathrm{g} / \mathrm{cm}^{3}, \gamma_{w}$ is surface water density, $\mathrm{g} / \mathrm{cm}^{3} ; b$ and $n$ are constants.

\section{Nomenclature}

$A, B, C=$ constants, dimensionless

$E_{d}=$ displacing efficiency, fraction

$E_{r}=$ oil recovery ratio, fraction

$E_{R}=$ ultimate recovery factor, fraction

$E_{V}=$ volumetric sweep efficiency, fraction

$f_{w}=$ water cut, fraction

$N=$ Original oil in place (OOIP), $\mathrm{m}^{3}$

$N_{p}=$ cumulative oil production, $\mathrm{m}^{3}$

$k_{r o}=$ oil relative permeability, fraction

$k_{r w}=$ water relative permeability, fraction

$R=$ oil recovery ratio, fraction

$S_{w}=$ water saturation, fraction

$S_{w d}=$ normalized water saturation, fraction

$S_{w i}=$ initial water saturation, fraction

$W O R=$ water oil ratio, dimensionless

$m, n, b=$ constants, dimensionless 


\section{References}

[1] Ershaghi, I., Omoregie O. (1978) A Method for Extrapolation of Cut vs. Recovery curve, JPT, (1978): 203-204.

[2] Lo, K. K. (1990) A Study of the Post-Breakthrough Characteristics of Waterfloods, SPE 20064 presented at the $60^{\text {th }}$ California Regional Meeting, Ventura, CA.

[3] Yortsos, Y. C., Choi, Y. and Yang, Z. (1997) Analysis and Interpretation of the Water-Oil Ratio in Waterfloods, SPE 38869 presented at SPE Annual Technical Conference and Exhibition, San Antonio, TX.

[4] B. Can, C. S. Kabir (2014) Simple tools for forecasting waterflood performance. Journal of Petroleum Science and Engineering, 120 (4): 111-118.

[5] LIU Shihua, GU Jianwei, YANG Renfeng (2011) New water-flooding characteristic curve at high water-cut stage. Journal of Liaoning Technical University (Natural Science), 30 (Suppl): 158-163.

[6] Song Zhaojie, Li Zhiping, Lai Fengpeng (2013) Derivation of water flooding characteristic curve for high water-cut oilfields. PETROLEUM EXPLORATION AND DEVELOPMENT, 40 (2): 201-208.

[7] HOU Jian, WANG Rong-rong, XIA Zhi-zeng (2013) Improvement of water displacement curve for water flooded oil reservoirs at ultra-high water cut stage. Journal of China University of Petroleum, 37 (6): 72-75.

[8] Wang Hua (2012) Application of improved water drive curve in recoverable reserves. PGRE, 19 (4): 84-86.

[9] Chen Yuanqian, Zou Cunyou, Zhang Feng (2011) Application of water drive curve method in oilfield development evaluation. Fault-Block Oil \& Gas Field, 18 (6): 769-771.

[10] Zhengming Yang (2009) A New Diagnostic Analysis Method for Waterflood Performance. SPE 113856, SPE Reservoir Evaluation \& Engineering, 2009 (4): 341-351.

[11] Akram A. H., Camilleri L. and Badr A. (2011) Production Forecasting in Heterogeneous Reservoirs without Reservoir Simulation, SPE 13696, paper presented at the SPE Middle East Oil and Gas Show and Conference held in Manama, Bahrain.

[12] XU F, MU L, WU X, et al (2014) New expression of oil/water relative permeability ratio vs. water saturation and its application in water flooding curve. Energy Exploration \& Exploitation, 32 (5): 817-830.

[13] CUI Chuanzhi, XU Jianpeng, WANG Duanping, et al (2015) A new water flooding characteristic curve at ultra-high water cut stage. Acta Petrolei Sinica, 36 (10): 1267-1271.

[14] LIU Zhibin, LIU Haohan (2015) An effective method to predict oil recovery in high water cut stage. Journal of Hydrodynamics, 27 (6): 988-995.

[15] WANG Jiqiang, SHI Chengfang, JI Shuhong, et al. (2017) New water drive characteristic curves at ultra-high water cut stage. Petroleum Exploration and Development, 44 (6): 955-960.

[16] Guo Y H, Zhang L, Yao J, et al. (2019) Mechanisms of water flooding characteristic curve upwarping at high water-cut stage and influencing factors. Chin Sci Bull, 64 (26): 27512760 .

[17] DOU Hong'en, ZHANG Hujun, SHEN Sibo (2019) Correct understanding and application of waterflooding characteristic curve. Petroleum Exploration and Development, 46 (4): 755-762.

[18] GAO Wenjun, YIN Rui, YANG Jing (2020) Establishment and theoretical basis of the new water-flooding characteristic curve. Acta Petrolei Sinica, 41 (3): 342-347. 